\title{
Role of endometriosis as a prognostic factor for post-progression survival in ovarian clear cell carcinoma
}

\author{
HIROKI ISHIBASHI ${ }^{1}$, MASASHI TAKANO ${ }^{2}$, MORIKAZU MIYAMOTO ${ }^{1}$, \\ HIROAKI SOYAMA ${ }^{1}$, HIROKO MATSUURA ${ }^{1}$, TADASHI AOYAMA ${ }^{1}$, \\ TOMOYUKI YOSHIKAWA ${ }^{2}$, KENTO KATO ${ }^{1}$, HITOSHI TSUDA ${ }^{3}$ and KENICHI FURUYA ${ }^{1}$ \\ Departments of ${ }^{1}$ Obstetrics and Gynecology, ${ }^{2}$ Clinical Oncology and ${ }^{3}$ Basic Pathology, \\ National Defense Medical College Hospital, Tokorozawa, Saitama 359-8513, Japan
}

Received June 16, 2017; Accepted September 8, 2017

DOI: $10.3892 /$ mco.2017.1468

\begin{abstract}
The clinical significance of coexistence of endometriosis (EM) in ovarian clear cell carcinoma (CCC) has not yet been determined. The aim of the present study was to analyze the correlation of endometriosis with clinicopathological factors in CCC. The cases with CCC that received primary debulking surgery at the present hospital between 1990 and 2013 were identified. Retrospective analysis was conducted to evaluate the association between complications with EM and clinicopathological features in CCC. Of the 105 cases enrolled in the study, 45 cases were complicated with EM, and 60 cases did not have EM (non-EM). The patients with EM were diagnosed at a younger age $(\mathrm{P}=0.03)$, and at earlier stages $(\mathrm{P}<0.01)$ compared with non-EM cases. Although there was no significant difference of progression-free survival $(\mathrm{P}=0.36)$, complications with EM were identified as an independent prognostic factor for overall survival $(\mathrm{OS} ; \mathrm{P}<0.01)$ by multivariate analysis. A total of 48 patients (45.7\%) developed recurrence: 18 patients in EM-group and 30 patients in non-EM group. There were no significant differences of clinicopathological factors in the treatment at recurrence between both groups. Recurrent cases in EM had significantly worse post-progression survival (PPS) compared with recurrent non-EM group $(\mathrm{P}<0.01)$. Multivariate analysis for PPS demonstrated that complications with EM $(\mathrm{P}<0.01)$ were identified as a worse prognostic factor. In CCC, the complication with EM was identified as a significant worse prognostic factor for PPS in recurrent cases. Additionally, EM was significantly associated with OS in all cases with CCC. Novel treatment strategies are therefore necessary for recurrent CCC, particularly for cases exhibiting EM.
\end{abstract}

Correspondence to: Dr Masashi Takano, Department of Clinical Oncology, National Defense Medical College Hospital, 3-2 Namiki, Tokorozawa, Saitama 359-8513, Japan

E-mail: mastkn@ndmc.ac.jp

Key words: clear cell carcinoma, endometriosis, progression-free survival, overall survival, survival post-progression

\section{Introduction}

Recently, the incidences of ovarian carcinoma have been increasing (1). The prognoses of ovarian carcinoma have not been improved in spite of development for anti-cancer treatment, particularly in advanced stages (2). Several predictive factors for prognoses in ovarian carcinomas have been identified: FIGO stage, residual tumor diameter, and histological subtypes, and so on $(3,4)$. Among all histological subtypes, clear cell carcinoma (CCC) has been recognized as a subtype showing worse prognoses (3). Additionally, CCC is a distinct subtype with lower response and short response duration even in responder against chemotherapy $(3,5,6)$.

Endometriosis is well-known as precursor of $\operatorname{CCC}(7,8)$, and there was a report suggesting that genetic back ground in $\mathrm{CCC}$ derived from endometriosis was different from those without endometriosis (7). Some reports have shown negative correlation of endometriosis with prognoses in CCC (9-11), and other investigations have shown positive association with better prognoses (12-15). So the clinical impact of the complication with endometriosis in upon prognosis of CCC has not been determined.

Recently, it has been pointed out that post-progression survival (PPS), defined as duration from the date of recurrence to the date of death, was relatively longer in ovarian cancers (16). Herein, we investigated the relationship with complication with endometriosis, and clinicopathological factors in CCC, including evaluation of PPS.

\section{Patients and methods}

Patients and treatment. The cases with CCC who received primary debulking surgery and adjuvant chemotherapy at our institution between 1990 and 2013 were identified, and medical charts of the cases were retrospectively reviewed.

The patients with endometriosis was defined as the coexistence with CCC and endometriosis in the same and/or heterolateral ovary, and/or coexistence with CCC and extraovarian endometriosis (EM-group) $(9,11,15)$. The patients without endometriosis were defined as non-EM group. Staging was evaluated according to International Federation of Gynecology 
Table I. Characteristics of the patients with ovarian clear cell carcinoma.

\begin{tabular}{lcc}
\hline Variables & $\begin{array}{c}\text { Patients associated with } \\
\text { endometriosis n=45 }\end{array}$ & $\begin{array}{c}\text { Patients without } \\
\text { endometriosis n=60 }\end{array}$ \\
\hline Age, mean \pm SD (range) & $51.0 \pm 9.5(35-74)$ & $55.5 \pm 9.0(32-75)$ \\
FIGO stage (\%) & $36(80.0)$ & $28(46.6)$ \\
I & $1(2.2)$ & $10(16.7)$ \\
II & $7(15.6)$ & $19(31.7)$ \\
III & $1(2.2)$ & $3(5.0)$ \\
IV & $38(84.5)$ & $42(70.0)$ \\
Residual tumor diameter at PDS & $1(2.2)$ & $5(8.3)$ \\
None $(\%)$ & $6(13.3)$ & $13(21.7)$ \\
$<1.0 \mathrm{~cm}$ & & $30(50.0)$ \\
$\geqq 1.0 \mathrm{~cm}$ & $18(40.0)$ & $30(50.0)$ \\
Recurrence $(\%)$ & $27(60.0)$ & 0.20 \\
Yes & & $16(26.7)$ \\
No & $16(35.6)$ & $44(73.3)$ \\
Adjuvant chemotherapy $(\%)$ & $29(64.4)$ & 0.33 \\
Taxane-platinum therapy ${ }^{\mathrm{a}}$ & & \\
Platinum-based therapy & &
\end{tabular}

SD, standard deviation; PDS, primary debulking surgery. ${ }^{a}$ Taxane-platinum therapy included paclitaxel plus carboplatin, and docetaxel plus carboplatin. ${ }^{b}$ Platinum-based therapy included cyclophosphamide plus platinum $(\mathrm{CP}), \mathrm{CP}$ plus doxorubicin, epirubicin plus platinum, and irinotecan plus platinum.

A

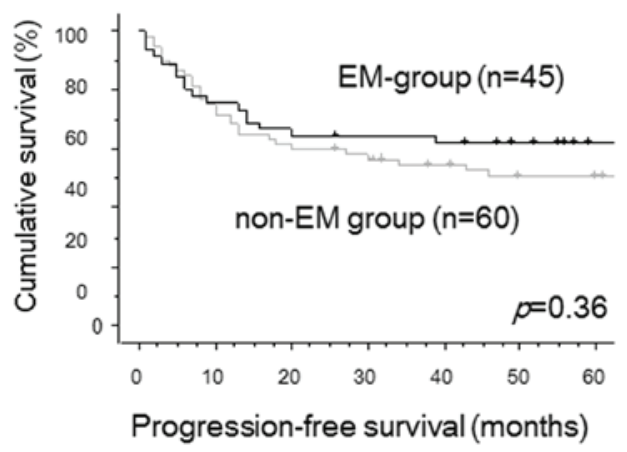

B

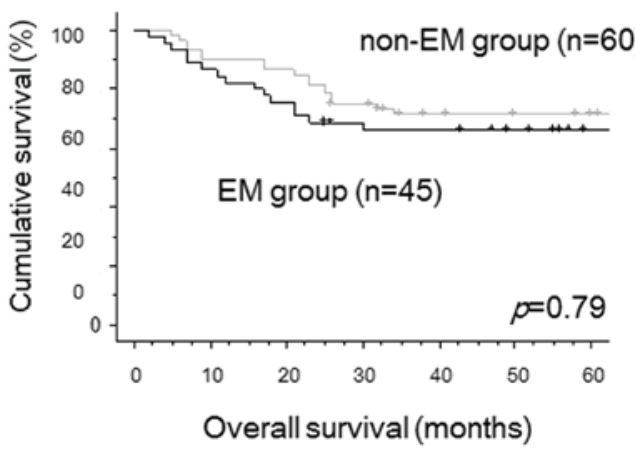

Figure 1. Progression-free survival (PFS) curves and overall survival (OS) curves of all CCC cases. (A) Progression-free survival curves of the cases with coexistence with endometriosis (EM-group) and those without endometriosis (non-EM group). There was no significant difference in $\mathrm{PFS}$ (P=0.36) between two groups. black line, EM-group; gray line, non-EM group. (B) Overall survival curves of the cases with coexistence with endometriosis (EM-group) and those without endometriosis (non-EM group). There was no significant difference in OS ( $\mathrm{P}=0.79)$ between two groups. Black line, EM-group; gray line, non-EM group.

and Obstetrics (FIGO) staging system 2014. Adjuvant chemotherapy was classified into two categories: Conventional platinum-based, and taxane-platinum chemotherapy. The regimens of conventional platinum-based chemotherapy included cyclophosphamide plus platinum (CP), CP plus doxorubicin (CAP), epirubicin plus platinum (EP), and irinotecan plus platinum. Taxane-platinum chemotherapy included paclitaxel plus carboplatin, and docetaxel plus carboplatin.

All cases received chemotherapy after primary debulking surgery. Patients were considered to be platinum-sensitive if the time from completion of primary chemotherapy regimen to disease recurrence/progression was more than six months, and the cases were regarded as platinum-resistant when the time from completion of primary chemotherapy to disease recurrence/progression was less than 6 months. Serum levels of tumor markers including CA125 were not used for judgement of response to chemotherapy. This study was approved by the institution review board of National Defense Medical College.

Statistical methods. The STAT View software ver 5.0 (SAS Institution, Cary, NC, USA) was used for statistical analysis. The $\chi^{2}$-test, Fisher's exact test, and Mann-Whitney U test were used to evaluate clinical significance of clinicopathological factors. Progression-free survival (PFS) was defined as the duration from the date of the primary surgery to the date of death or recurrence/progression of the diseases. Overall 
Table II. Multivariate analyses for progression-free survival and overall survival in all patients with ovarian clear cell carcinoma.

\begin{tabular}{|c|c|c|c|c|}
\hline \multirow[b]{2}{*}{ Variables } & \multicolumn{2}{|c|}{ Progression-free survival } & \multicolumn{2}{|c|}{ Overall survival } \\
\hline & $\operatorname{HR}(95 \% \mathrm{CI})$ & P-value & $\mathrm{HR}(95 \% \mathrm{CI})$ & P-value \\
\hline Age (years) & & & & 0.69 \\
\hline$>53$ vs. $\leq 53$ & $1.00(0.44-2.30)$ & 0.99 & $0.69(0.51-2.72)$ & \\
\hline FIGO stage & & & & 0.12 \\
\hline I, II vs. III, IV & $0.45(0.20-1.00)$ & 0.05 & $0.5(0.20-1.21)$ & \\
\hline Residual tumor at PDS & & & & 0.27 \\
\hline None vs. macroscopic disease & $1.58(0.70-3.58)$ & 0.27 & $1.64(0.68-4.03)$ & \\
\hline Endometriosis & & & & $<0.01$ \\
\hline $\mathrm{EM}^{\mathrm{a}}$ vs. non-EM ${ }^{\mathrm{b}}$ & $1.37(0.69-2.71)$ & 0.36 & $3.02(1.41-6.52)$ & \\
\hline Adjuvant chemotherapy & & & & 0.58 \\
\hline Taxane-platinum $^{\mathrm{c}}$ vs. platinum-based ${ }^{\mathrm{d}}$ & $1.28(0.53-3.03)$ & 0.58 & $0.80(0.29-1.91)$ & \\
\hline
\end{tabular}

Table III. Characteristics of patients with recurrent ovarian clear cell carcinoma.

\begin{tabular}{lcc}
\hline Variables & $\begin{array}{c}\text { Recurrent patients associated } \\
\text { with endometriosis } n=18\end{array}$ & $\begin{array}{c}\text { Recurrent patients without } \\
\text { endometriosis n=30 }\end{array}$ \\
\hline Age, mean \pm SD (range) & $51.0 \pm 7.0(38-63)$ & $55.0 \pm 9.0(36-75)$ \\
FIGO stage $(\%)$ & $9(50.0)$ & $9(30.0)$ \\
I & $1(5.6)$ & $5(16.7)$ \\
II & $7(38.8)$ & $14(46.7)$ \\
III & $1(5.6)$ & $2(6.6)$ \\
IV & & $18(60.0)$ \\
Residual tumor diameter at PDS $(\%)$ & $11(61.1)$ & $2(6.7)$ \\
None & $1(5.6)$ & $10(33.3)$ \\
$<1.0$ cm & $6(33.3)$ & $26(86.6)$ \\
$\geqq 1.0$ cm & & $2(6.7)$ \\
Treatment at recurrence $(\%)$ & $11(61.1)$ & $2(6.7)$ \\
Chemotherapy & & \\
Secondary debulking surgery & $2(11.1)$ & $14(46.7)$ \\
Not done & $5(27.8)$ & $16(53.3)$ \\
Platinum-sensitivity $(\%)$ & & 0.99 \\
Sensitive & $8(44.4)$ & 0.08 \\
Resistant & $10(55.6)$ & 0.99 \\
\hline
\end{tabular}

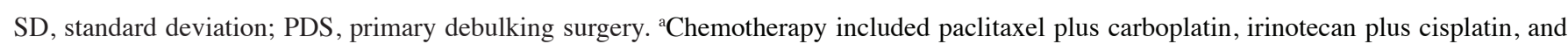

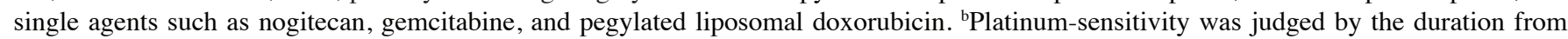
completion of primary chemotherapy regimen to disease recurrence/progression.

survival (OS) was defined as the duration from the date of the primary surgery to the date of death. Post-progression survival (PPS) was defined as duration from the date of recurrence/progression of the disease until the date of death. PFS, OS, and PPS curves were generated using the method of Kaplan-Meier. Comparisons of the survival distribution were made with log-rank test. Cox proportional hazards model was used for multivariate analysis of PFS, OS and PPS. A P-value of $<0.05$ was considered to be statistically significant.

\section{Results}

In this study, a total of 105 cases were enrolled. The median follow-up time was 60 months (range, 2-276 months). Of all 

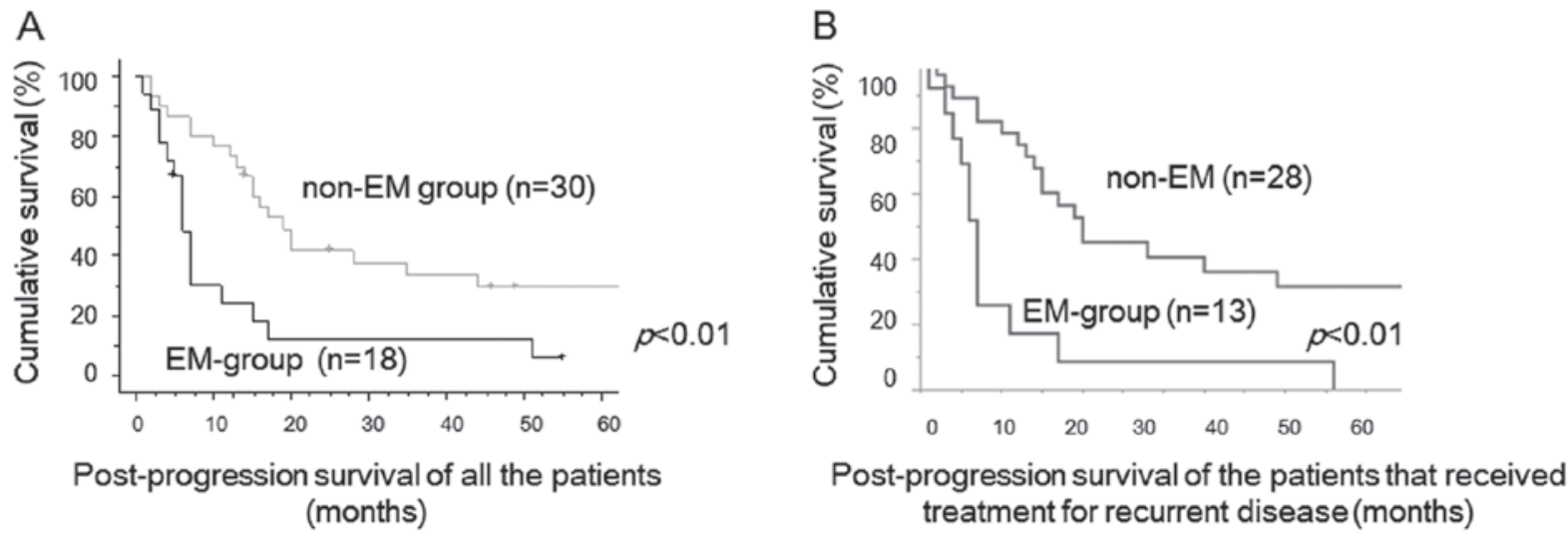

Figure 2. (A) Post-progression survival (PPS) curves of recurrent CCC cases with coexistence with endometriosis (EM-group) and those without endometriosis (non-EM group). Recurrent cases in EM-group had significantly worse post-progression survival compared with recurrent cases in non-EM group ( $\mathrm{P}<0.01$ ). black line, EM-group; gray line, non-EM group. (B) Post-progression survival (PPS) curves of the patients that received treatment for recurrent disease. EM-group had significantly worse PPS compared with EM group $(\mathrm{p}<0.01)$.

Table IV. Multivariate analysis for post-progression survival in recurrent cases with ovarian clear cell carcinoma.

\begin{tabular}{|c|c|c|}
\hline \multirow[b]{2}{*}{ Variables } & \multicolumn{2}{|c|}{ Post-progression survival } \\
\hline & HR $(95 \% \mathrm{CI})$ & P-value \\
\hline Age (years) & & 0.71 \\
\hline$>53$ vs. $\leq 53$ & $0.87(0.43-1.76)$ & \\
\hline FIGO stage & & 0.24 \\
\hline I, II vs. III, IV & $0.57(0.22-1.47)$ & \\
\hline Residual tumor at PDS & & 0.53 \\
\hline None vs. macroscopic disease & $0.74(0.29-1.88)$ & \\
\hline Endometriosis & & $<0.01$ \\
\hline $\mathrm{EM}^{\mathrm{a}}$ vs. non-EM ${ }^{\mathrm{b}}$ & $4.57(1.93-10.97)$ & \\
\hline Platinum-sensitivity $^{c}$ & & $<0.01$ \\
\hline Sensitive vs. resistant & $0.32(0.14-0.73)$ & \\
\hline Treatment at recurrence & & 0.43 \\
\hline Done vs. not done & $1.46(0.59-4.18)$ & \\
\hline 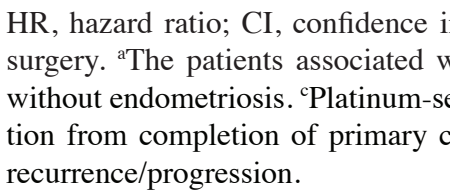 & $\begin{array}{l}\text { erval; PDS, primary } \\
\text { h endometriosis. }{ }^{\mathrm{b}} \mathrm{Tl} \\
\text { sitivity was judged b } \\
\text { motherapy regimen }\end{array}$ & $\begin{array}{l}\text { debulking } \\
\text { Patients } \\
\text { the dura- } \\
\text { to disease }\end{array}$ \\
\hline
\end{tabular}

cases, 45 cases $(42.8 \%)$ were classified into EM-group, and 60 cases $(57.1 \%)$ were in non-EM group (Table I). The clinicopathological factors of EM and non-EM patients were shown in Table I. EM-group patients were diagnosed at younger ages $(\mathrm{P}=0.03)$, and at earlier stages $(\mathrm{P}<0.01)$, compared with non-EM cases. Other factors such as residual tumor and adjuvant therapy regimens were not statistically different between two groups. There were no significant differences in PFS ( $\mathrm{P}=0.36$, Fig. 1A) and $\mathrm{OS}(\mathrm{P}=0.79$, Fig. 1B) between two groups by univariate analysis. Using multivariate analyses for PFS, FIGO stage was identified as the only independent prognostic factor. The complication with endometriosis was selected as the only independent prognostic factor for OS in multivariate analyses (Table II).
During the study period, 48 cases developed recurrence: $18(40 \%)$ in 45 EM-group cases and $30(50 \%)$ in 60 non-EM cases. The clinicopathological features of recurrent cases were shown in Table III. No cases received radiation therapy and most of the cases received chemotherapy. Some cases received secondary debulking surgery for recurrent tumors. There were no significant differences of clinicopathological factors including age, FIGO stage, debulking status at primary debulking surgery, and platinum-sensitivity between two groups. PPS of recurrent EM-group cases was significantly worse than that of recurrent non-EM cases ( $\mathrm{P}<0.01$, Fig. $2 \mathrm{~A}$ ). Median PPS was 6 months in recurrent EM-group, 18 months in recurrent non-EM cases, respectively. PPS of the patients that received therapeutic modality for recurrent tumors were shown in Figure 2B. PPS of EM-group cases was also significantly worse than that of non-EM cases ( $<<0.01$, Fig. $2 B$ ).

Multivariate analysis for PPS revealed that complication with endometriosis was an independent worse prognostic factor (Hazard ratio, 4.57; 95\% Confidence Interval, 1.93-10.97; $\mathrm{P}<0.01$ ), in addition to platinum-sensitivity (Table IV).

\section{Discussion}

In the present study, the cases with EM were diagnosed at younger age and at earlier stages. Nevertheless, the complication with endometriosis was not a predictive factor of prognosis including PFS and OS. Until now, several studies had evaluated clinical significance of the correlation with endometriosis in prognoses of CCC, however, the conclusions have not been determined $(7,11,14,16)$. According to recent meta-analysis conducted by Kim et al, the complication with endometriosis was not related with prognosis in all subtypes of ovarian cancers (7).

PPS of clear cell carcinoma was considered to be shorter than that of serous carcinoma (17). This reason was caused by not only lower response rate, regardless of platinum-sensitivity status, but also short response duration in cases with recurrent CCC $(3,5,9)$. In general, PPS of ovarian carcinomas including all histological subtypes was $>20$ months (18). However, PPS of CCC was much shorter, especially in the cases with endometriosis. A report suggested that PPS was more highly associated than PFS 
with OS in the first-line chemotherapy for advanced epithelial ovarian cancer (18). Short PPS in CCC could have led to shorter OS in CCC cases, especially in EM-group patients. Although genetic difference in the tissue specimens was not evaluated in the present study, a report suggested that some patients carried driver mutations in ARID1A, PIK3CA, KRAS genes in benign deep infiltrating endometriosis (19). It is speculated that tumor samples of EM-group had potentially aggressive phenotype compared with non-EM group tumors.

Although there was no difference in PFS between EM-group and non-EM group, PPS was significantly shorter in EM-group patients. Primary therapy using anti-cancer agents might alter genetic profile in CCC tumors, and cause refractory phenotype after recurrence. A report suggested CCC patients with Met gene amplification showed chemoresistant phenotype and worse prognosis (19). Thus, the alteration of genetic profiles affected by primary therapy might influence PPS in the patients with CCC. Additionally, phosphatidylinositol-3-kinase (PI3K)/Akt signaling pathway, and the receptor tyrosine kinase (RTK)/Ras signaling pathway were identified as prognostic biomarkers for CCC tumors using whole-genome sequencing (21). Novel chemotherapeutic agents inhibiting these pathways might improve survival of the CCC patients.

The limitation of this study included a retrospective study and a small number of the patients enrolled in a single-institutional analysis. Further prospective investigation is needed to confirm the impact of complication with endometriosis upon PPS of CCC patients.

In conclusion, the complication with endometriosis was the independent poor prognostic factor for PPS in CCC. Longer PPS could have led to longer OS in EM-group CCC. Further prospective investigation is necessary to confirm the significance of complication with endometriosis on PPS in CCC and develop the new therapy for recurrent $\mathrm{CCC}$ with endometriosis should also be considered.

\section{Acknowledgements}

The present study has been edited and corrected by an experienced proofreader who is a native speaker of English and who is under the direct supervision of Honyaku Center Inc. (Osaka, Japan).

\section{References}

1. Permuth-Wey J and Sellers TA: Epidemiology of ovarian cancer. Methods Mol Biol 472: 413-437, 2009.

2. Heintz AP, Odicino F, Maisonneuve P, Quinn MA, Benedet JL, Creasman WT, Ngan HY, Pecorelli S and Beller U: Carcinoma of the ovary. FIGO 26th annual report on the results of treatment in gynecological cancer. Int J Gynecol Obstet 95 (Suppl 1): S161-S192, 2006.

3. Takano M, Sugiyama T, Yaegashi N, Sakuma M, Suzuki M, Saga Y, Kuzuya K, Kigawa J, Shimada M, Tsuda H, et al: Low response rate of second-line chemotherapy for recurrent or refractory clear cell carcinoma of the ovary: A retrospective Japan clear cell carcinoma study. Int J Gynecol Cancer 18: 937-942, 2008.

4. Colombo PE, Mourregot A, Fabbro M, Gutowski M, Saint-Aubert B, Quenet F, Gourgou S and Rouanet P: Aggressive surgical strategies in advanced ovarian cancer: A monocentric study of 203 stage IIIC and IV patients. Eur J Surg Oncol 35: 135-143, 2009.

5. Takano M, Goto T, Kato M, Sasaki N, Miyamoto M and Furuya K: Short response duration even in responders to chemotherapy using conventional cytotoxic agents in recurrent or refractory clear cell carcinomas of the ovary. Int J Clin Oncol 18: 556-557, 2013.
6. Miyamoto M, Takano M, Goto T, Kato M, Sasaki N, Tsuda H and Furuya K: Clear cell histology as a poor prognostic factor for advanced epithelial ovarian cancer: A single institutional case series through central pathologic review. J Gynecol Oncol 24: 37-43, 2013.

7. Kim HS, Kim TH, Chung HH and Song YS: Risk and prognosis of ovarian cancer in women with endometriosis: A meta-analysis. Br J Cancer 110: 1878-1890, 2014.

8. Pearce CL, Templeman C, Rossing MA, Lee A, Near AM, Webb PM, Nagle CM, Doherty JA, Cushing-Haugen KL, Wicklund KG, et al: Association between endometriosis and risk of histological subtypes of ovarian cancer: A pooled analysis of case-control studies. Lancet Oncol 13: 385-394, 2012.

9. Kim HS, Kim MA, Lee M, Suh DH, Kim K, No JH, Chung HH, Kim YB and Song YS: Effect of endometriosis on the prognosis of ovarian clear cell carcinoma: A two-center cohort study and meta-analysis. Ann Surg Oncol 22: 2738-2745, 2015.

10. Kumar S, Munkarah A, Arabi H, Bandyopadhyay S, Semaan A, Hayek K, Garg G, Morris R and Ali-Fehmi R: Prognostic analysis of ovarian cancer associated with endometriosis. Am J Obstet Gynecol 204: 63. e1-e7, 2011.

11. Orezzoli JP, Russell AH, Oliva E, Del Carmen MG, Eichhorn J and Fuller AF: Prognostic implication of endometriosis in clear cell carcinoma of the ovary. Gynecol Oncol 110: 336-344, 2008.

12. Komiyama S, Aoki D, Tominaga E, Susumu N, Udagawa Y and Nozawa S: Prognosis of Japanese patients with ovarian clear cell carcinoma associated with pelvic endometriosis: Clinicopathologic evaluation. Gynecol Oncol 72: 342-346, 1999.

13. Erzen M, Rakar S, Klancnik B and Syrjänen K: Endometriosis-associated ovarian carcinoma (EAOC): An entity distinct from other ovarian carcinomas as suggested by a nested case-control study. Gynecol Oncol 83: 100-108, 2001.

14. Melin A, Lundholm C, Malki N, Swahn ML, Sparen P and Bergqvist A: Endometriosis as a prognostic factor for cancer survival. Int J Cancer 129: 948-955, 2011.

15. Bai H, Cao D, Yuan F, Sha G, Yang J, Chen J, Wang Y, Zhang Z and Shen K: Prognostic value of endometriosis in patients with stage I ovarian clear cell carcinoma: Experiences at three academic institutions. Gynecol Oncol 143: 526-531, 2016.

16. Ye S, Yang J, You Y, Cao D, Bai H, Lang J, Chen J and Shen K: Comparative study of ovarian clear cell carcinoma with and without endometriosis in People's Republic of China. Fertil Steril 102: 1656-1662, 2014.

17. Kajiyama H, Shibata K, Mizuno M, Yamamoto E, Fujiwara S, Umezu T, Suzuki S, Nakanishi T, Nagasaka T and Kikkawa F: Postrecurrent oncologic outcome of patients with ovarian clear cell carcinoma. Int J Gynecol Cancer 22: 801-806, 2012.

18. Shimokawa M, OhkiM and Kaku T: Correlation of progression-free and post-progression survival with overall survival in phase III trials of first-line chemotherapy for advanced epithelial ovarian cancer. Eur J Gynaecol Oncol 36: 370-375, 2015.

19. Anglesio MS, Papadopoulos N, Ayhan A, Nazeran TM, Noë M, Horlings HM, Lum A, Jones S, Senz J, Seckin T, Ho J, Wu RC, Lac V, Ogawa H, Tessier-Cloutier B, Alhassan R, Wang A, Wang Y, Cohen JD, Wong F, Hasanovic A, Orr N, Zhang M, Popoli M, McMahon W, Wood LD, Mattox A, Allaire C, Segars J, Williams C, Tomasetti C, Boyd N, Kinzler KW, Gilks CB, Diaz L, Wang TL, Vogelstein B, Yong PJ, Huntsman DG and Shih IM. Cancer-Associated Mutations in Endometriosis without Cancer. N Engl J Med 376: 1835-48, 2017.

20. Yamashita Y, Akatsuka S, Shinjo K, Yatabe Y, Kobayashi H, Seko H, Kajiyama H, Kikkawa F, Takahashi T and Toyokuni S: Met is the most frequently amplified gene in endometriosis-associated ovarian clear cell adenocarcinoma and correlates with worsened prognosis. PLoS One 8: e57724, 2013.

21. Itamochi H, Oishi T, Oumi N, Takeuchi S, Yoshihara K, Mikami M, Yaegashi N, Terao Y, Takehara K, Ushijima K, Watari H, Aoki D, Kimura T, Nakamura T, Yokoyama Y, Kigawa J and Sugiyama T. Br J Cancer 2017; doi: 10.1038/ bjc.2017.228 (Epub ahead of print). 